\title{
O PAPEL DO INSTITUTO NACIONAL DE ESTUDOS E PESQUISAS EDUCACIONAIS ANÍSIO TEIXEIRA (INEP) NA REFORMA GERENCIAL DOS SISTEMAS PÚBLICOS DE ENSINO NO BRASIL*
}

Thiago de Jesus Esteves

José dos Santos Souza

\section{Introdução}

O capítulo tem como objeto de análise o processo de transformação do Instituto Nacional de Estudos e Pesquisas Educacionais Anísio Teixeira (INEP) em agência de avaliação da educação brasileira no contexto das reformas gerenciais implementadas a partir do governo de Fernando Henrique Cardoso (1995-2002) e aperfeiçoadas pelos governos de Lula da Silva (2003-2010) e Dilma Roussef (20112016). Seu objetivo é evidenciar o papel do INEP na reforma gerencial da educação. A promulgação da Lei no 9.394/1996, desencadeou o processo de definição de parâmetros de qualidade para nortear as políticas educacionais, de modo a induzir a adoção de mecanismos de coleta de dados e de estratégias sistêmicas de avaliação de desempenho escolar pelas instituições de ensino, tendo os princípios da Nova Gestão Pública como norteadores. Este processo significou a extensão da reforma gerencial para a gestão dos sistemas públicos de ensino. A reestruturação do INEP, além de readequar suas funções, elevou seu status para órgão público estratégico na reforma gerencial dos sistemas públicos de ensino. O conteúdo do artigo é parte dos resultados de um projeto investigativo mais amplo que se caracteriza por sistematizar uma pesquisa básica, de análise qualitativa, de caráter explicativo, que se insere na categoria de estudo documental cujos fundamentos teóricos e metodológicos se situam no materialismo histórico e dialético.

A década de 1970 foi marcada por uma nova crise do capitalismo mundial. Como resultado dessa crise, frações da classe burguesa promoveram uma ampla redefinição das políticas públicas, sobretudo, aquelas relacionadas a educação, saúde e renda, com o objetivo de reorientar o fundo público. Nesse contexto, desde o final da década de 1980, o campo educacional brasileiro vem passando por profundas transformações estruturais, que objetivam garantir a recomposição do capital (SOUZA, 2017). Tais mudanças vêm ocorrendo, principalmente, a partir de um processo de articulação entre frações do bloco no poder e o capital internacional. Nesse processo, tem sido notável a participação dos organismos internacionais - a exemplo da Comissão Econômica para a América Latina e o Caribe (CEPAL), da Organização das Nações Unidas para a Educação, Ciência e Cultura (UNESCO), do Grupo Banco Mundial (GBM) e mais recentemente da Organização para a Cooperação e Desenvolvimento Econômico (OCDE) - no estabelecimento de políticas educacionais, que visam em última instância a conformação da classe trabalhadora

* DOI - 10.29388/978-65-86678-87-1-0.f.54-67 
por meio de uma pedagogia política do capital (LIMA, 2002; MACEDO, 2017; TOMMASI, 1996).

Com o objetivo de garantir a implementação do ideário da nova gestão pública, em meados da década de 1990, as frações da classe dominante que compunham o bloco no poder se articularam em torno de uma série de reformas estruturais que pudessem garantir a implementação do projeto político e pedagógico do capital. Para garantir a implementação desse projeto e capitanear tal empreitada era necessário um intelectual orgânico com legitimidade frente a classe trabalhadora e aos diferentes partidos que disputam a hegemonia em torno do campo educacional. Assim, foi sancionada a Lei no 9.448/1997, que reestruturou o Instituto Nacional de Estudos e Pesquisas Educacionais Anísio Teixeira (INEP) e tornou essa autarquia vinculada ao Ministério da Educação (MEC), no organismo responsável por regular os sistemas educacionais brasileiros, formulando, sistematizando e divulgando o projeto político e pedagógico do capital.

Nessa perspectiva, do ponto de vista metodológico, destacamos que este artigo é parte dos resultados de um projeto investigativo mais amplo que se caracteriza por sistematizar uma pesquisa básica, de análise qualitativa, de caráter explicativo, que se insere na categoria de estudo documental cujos fundamentos teóricos e metodológicos se situam no materialismo histórico e dialético. A propósito, após a realização do levantamento bibliográfico, realizado para verificar o tratamento dado pela literatura da área da educação ao papel do INEP na reforma gerencial do campo educacional brasileiro, chama nossa atenção, que apesar de sua relevância para a área educacional brasileira são poucos os trabalhos acadêmicos que se propõem a compreender o papel do INEP enquanto agência de avaliação das políticas educacionais.

\section{Criação do Instituto Nacional de Pedagogia e Institucionalização da Política Educacional Brasileira}

O Instituto Nacional de Pedagogia, foi criado durante a reforma burocrática do aparelho do Estado brasileiro empreendida pelo regime do Estado Novo, por iniciativa do ministro Gustavo Capanema e proposta do educador

Lourenço Filho, em meio a reorganização do Ministério da Educação e Saúde Pública (SAVIANI, 2013). Para além de alterar a nomenclatura do Ministério da Educação e Saúde Pública, que passou a ser denominado como Ministério da Educação e Saúde, a sanção da Lei no 378/1937, estabeleceu em seu Artigo 39 que:

Art. 39. Fica creado o Instituto Nacional de Pedagogia, destinado a realizar pesquisas sobre os problemas do ensino, nos seus differentes aspectos.

Paragrapho unico. Fica instituida, como parte integrante do Instituto Nacional de Pedagogia, a Commissão de Litetura Infantil, que terá por objectivo estudar o problema da literatura destinada ás crianças e aos adolescentes (BRASIL, 1937, s/p). 
Mesmo sem estabelecer as atribuições do Instituto Nacional de Pedagogia, a Lei $n$ o 387/1937 (BRASIL, 1937), instituiu uma estrutura organizacional mínima para o órgão ao criar sete cargos de Diretor padrão N. Apesar de formalmente criado, nenhuma medida foi tomada para efetivar a implantação desse órgão. Foi somente com a publicação do Decreto-Lei no 580/1938, que o Instituto Nacional de Pedagogia, teve as suas atribuições definidas, bem como a nomenclatura alterada para Instituto Nacional de Estudos Pedagógicos. O Decreto-Lei no 580/1938, em seu artigo segundo, estabeleceu como competências do Instituto Nacional de Estudos Pedagógicos: a) organizar documentação relativa à história e ao estudo atual das doutrinas e das técnicas pedagógicas, bem como das diferentes espécies de instituições educativas; $b$ ) manter intercâmbio, em matéria de pedagogia, com as instituições educacionais do país e do estrangeiro; c) promover inquéritos e pesquisas sobre todos os problemas atinentes à organização do ensino, bem como sobre os vários métodos e processos pedagógicos; d) promover investigações no terreno da psicologia aplicada à educação, bem como relativamente ao problema da orientação e seleção profissional; e) prestar assistência técnica aos serviços estaduais, municipais e particulares de educação, ministrando-lhes, mediante consulta ou independentemente desta, esclarecimentos e soluções sobre os problemas pedagógicos; e f) divulgar, pelos diferentes processos de difusão, os conhecimentos relativos à teoria e à práticas pedagógicas.

Esta multiplicidade de funções, como indica Saviani (2012), se concentram, além da manutenção de intercâmbio com instituições educacionais do país e exterior, nas áreas de levantamento e guarda de documentação, inquéritos e pesquisas das instituições educacionais e das doutrinas pedagógicas, assistência técnica e divulgação de conhecimentos relativos à teoria e a prática pedagógica. Como salientam Mendonça e Xavier (2008), foi graças a essa variedade de funções que o Instituto Nacional de Estudos Pedagógicos acabou se tornado "uma espécie de mini ministério, no interior do próprio Ministério da Educação e Cultura (MEC)". Tal afirmação, evidencia que desde a definição das suas funções em 1938, o Instituto Nacional de Estudos Pedagógicos possuía um papel de destaque para a definição das políticas educacionais do governo federal.

Para dirigir o Instituto Nacional de Estudos Pedagógicos, o ministro da educação e saúde, Gustavo Capanema, convidou o idealizador desse órgão, o educador paulista Manuel Lourenço Filho (1938-1946). Assim, em agosto de 1938, Lourenço Filho, membro da Associação Brasileira de Educação (ABE) e um dos expoentes do movimento Escola Nova no Brasil, toma posse como primeiro diretorgeral do Instituto Nacional de Estudos Pedagógicos.

A despeito da multiplicidade de funções atribuídas ao Instituto Nacional de Estudos Pedagógicos, em contradição com os objetivos da reforma do aparelho do Estado em curso, nesse período, a sua estrutura organizacional era limitada, conforme Mariani (1982), ao diretor geral e três outros diretores que ocupavam algumas salas do Edifício Calabouço, então sede do Ministério da Educação e Saúde. Foi somente em 1943, com a inauguração da nova sede do Ministério da Educação e Saúde, o atual Palácio Gustavo Capanema - no qual ocupou o 10 andar - é que o 
Instituto Nacional de Estudos Pedagógicos passou a contar com uma estrutura física condizente com as suas múltiplas funções.

Apesar dessas dificuldades, foi sob a direção de Lourenço Filho, que foram institucionalizadas duas funções que acompanham o INEP ao longo de sua história: atuar como formador de intelectuais afinados com o ideário do capital internacional e de difusor, na esfera do Estado, dos princípios, diretrizes e práticas da pedagogia política do capital. Esses elementos são materializados por meio da oferta de cursos de especialização e capacitação de professores, organização da biblioteca pedagógica, do serviço de documentação e legislação educacional brasileira, bem como pela criação em 1941, da Revista Brasileira de Estudos Pedagógicos (RBEP). Para Mariani (1982), o objetivo da RBEP era divulgar os estudos e pesquisas realizados pelos pesquisadores do instituto, bem como outros considerados relevantes para a compreensão das questões educacionais no Brasil, bem como o pensamento pedagógico nacional e internacional.

Em outubro de 1945, com a deposição de Getúlio Vargas e o fim do regime do Estado Novo, Lourenço Filho foi substituído na Diretoria-Geral do Instituto Nacional de Estudos Pedagógicos pelo advogado e educador piauiense Murilo Braga de Carvalho.

Durante a gestão de Murilo Braga de Carvalho (1946-1952), o Instituto Nacional de Estudos Pedagógicos passou por significativas modificações, assumindo funções de órgãos que foram extintos ou incorporados a sua estrutura. Com essa reestruturação, foram agregadas novas funções, como as atribuições da extinta Diretoria do Ensino Primário e Normal e a administração dos recursos do Fundo Nacional do Ensino Primário, que incluía a construção de escolas em zonas rurais, áreas de colonização estrangeira e de fronteiras, o que levou a diretoria-geral a concentrar esforços em pesquisas sobre modelos de edifícios que fossem adequados para grupos escolares, escolas isoladas e escolas normais.

Foi criado ainda, um setor de Aperfeiçoamento do Magistério, com o objetivo de ofertar cursos de especialização com oferecimento de bolsas de estudo para professores primários do interior do país. A necessidade de centrar esforços nessas novas funções acabaram levando a direção do Instituto Nacional de Estudos Pedagógicos a preterir as atribuições relativas à promoção de pesquisas educacionais. Com isso, permaneceram sob incumbência do órgão apenas alguns serviços de documentação e a publicação de catálogos com oportunidades para a carreira do magistério (MARIANI, 1982).

\subsection{O INEP nos anos de Anísio Teixeira}

O prematuro falecimento de Murilo Braga de Carvalho, em um acidente aéreo quando estava a serviço do governo brasileiro, levou o ministro da educação e saúde, Ernesto Simões Filho, a convidar para o cargo de Diretor Geral do Instituto Nacional de Estudos Pedagógicos, o responsável pela concepção e Secretário-Geral da Campanha de Aperfeiçoamento do Pessoal de Nível Superior, posteriormente 
renomeada como Coordenação de Pessoal de Nível Superior (CAPES), Anísio Spínola Teixeira (SAVIANI, 2013; VIANA FILHO, 2008).

Quando foi convidado para assumir a Direção-Geral do Instituto Nacional de Estudos Pedagógicos, o educador baiano Anísio Teixeira já possuía uma destacada carreira na área educacional no país e no exterior. Foi um dos principais teóricos do movimento da Escola Nova, sendo o responsável por introduzir o pensamento do pedagogo estadunidense John Dewey no país. Anísio Teixeira ocupou os cargos de Diretor-Geral da Instrução Pública do estado da Bahia (1924-1928), Diretor-Geral da Instrução Pública do Distrito Federal (19311935), Conselheiro de Educação Superior da UNESCO (1946-1947), Secretário da Educação do estado da Bahia (1947-1951) e Secretário-Geral da CAPES (1951-1964), função que acumulou com a Direção-Geral do Instituto Nacional de Estudos Pedagógicos (1952-1964).

Anísio Teixeira se tornou o mais longevo dirigente da história do INEP, tendo ocupado o cargo por 12 anos. Esse período foi marcado, segundo Bonamino, por "uma certa autonomia com relação ao poder político, que propiciava aos cientistas e educadores envolvidos a possibilidade de manter um distanciamento crítico das políticas oficiais" (BONAMINO, 2002, p. 115). Em seu discurso de posse, como DiretorGeral do Instituto Nacional de Estudos Pedagógicos, proferido em 04 de julho de 1952, após apresentar um diagnóstico da situação em que se encontravam o ensino básico, o ensino secundário e o ensino superior do país, Anísio Teixeira relembrou do papel dessa instituição para a educação nacional e anunciou que as pesquisas educacionais passariam a ter destaque em sua gestão. Ainda em seu discurso de posse, Anísio Teixeira reconheceu que o papel que vinha sendo desempenhado pelo INEP estava aquém das atividades esperadas do Instituto Nacional de Estudos Pedagógicos, sobretudo, no tocante a melhoria da educação ofertada pelos sistemas educacionais nacionais. Por fim, Anísio Teixeira apresentou as diretrizes que norteariam sua gestão à frente desse órgão:

Até o momento, não temos passado, de modo geral, do simples censo estatístico da educação. É necessário levar o inquérito às práticas educacionais. Procurar medir a educação, não somente em seus aspectos externos, mas em seus processos, métodos, práticas, conteúdos e resultados reais obtidos. Tomados os objetivos da educação, em forma analítica, verificar, por meio de amostras bem planejadas, como e até que ponto vem a educação conseguindo atingi-los.

Cumprir-nos-á, assim e para tanto, medir o sistema educacional em suas dimensões mais íntimas, revelando ao país não apenas a quantidade das escolas, mas a sua qualidade, o tipo de ensino que ministram, os resultados a que chegam no nível primário, no secundário e mesmo no superior (TEIXEIRA, 1952, s/p).

A importância dispensada aos levantamentos educacionais e a pesquisa social, foram dois aspectos significativos, que marcaram a gestão de Anísio Teixeira à frente do Instituto Nacional de Estudos Pedagógicos, sobretudo, o destaque para a pluralida- 
de teórico-metodológica com que eram realizadas essas abordagens (BONAMINO, 2002).

Com o objetivo de ordenar o trabalho dos diversos setores existentes, Anísio Teixeira editou a Portaria no 32, de 11 de novembro de 1953, que criou o Centro de Documentação Pedagógica. Tal centro foi constituído pela Seção de Documentação e Intercâmbio (SDI), Seção de Inquéritos e Pesquisas (SIP), Seção de Organização Escolar (SOE), Seção de Orientação Educacional e Profissional (SOEP) e a Biblioteca Pedagógica Murilo Braga (BP).

Com o propósito de dotar o Instituto Nacional de Estudos Pedagógicos de uma estrutura nacional que permitisse a concretização dos objetivos estabelecidos pelo Decreto-Lei no 580/1938 e reafirmados em seu discurso de posse, Anísio Teixeira, atuou na concepção de um Centro Brasileiro de Pesquisas Educacionais (CBPE). Para atender a essa finalidade, é editado o Decreto $n$ o 38.460/1955, que instituiu o CBPE, juntamente com cinco Centros Regionais de Pesquisas Educacionais, que se localizariam nas seguintes cidades: Rio de Janeiro (RJ), Recife (PE), Salvador (BA), São Paulo (SP), Belo Horizonte (MG) e Porto Alegre (RS).

O CBPE e os Centros Regionais de Pesquisas Educacionais acabaram incorporando as atividades de estudo e documentação, bem como a Campanha do Livro Didático (CALDEME), a Campanha dos Materiais de Ensino (CILEME) e a assistência técnica do Programa de Aperfeiçoamento do Magistério, que até então eram desenvolvidos diretamente pelo Instituto Nacional de Estudos Pedagógicos. Para atuar como corpo dirigente desses centros, Anísio Teixeira escolheu, negociou e convenceu pessoalmente um renomado grupo de intelectuais reconhecidos, tanto nacional, como internacionalmente, a aceitarem participar desta empreitada (VIANA FILHO, 2008). Consideramos essa camada dirigente como intelectuais na concepção de Gramsci (1991), por entendermos que um dos objetivos essenciais do projeto do CBPE e dos Centros Regionais de Pesquisas Educacionais, era possibilitar a criação de diferentes camadas de intelectuais, que pudessem conceber políticas públicas voltadas para a conformação da classe trabalhadora e assim dar homogeneidade ao projeto de pedagogia política do capital. Os intelectuais orgânicos teriam, assim, o papel de garantir, tanto política como institucionalmente, o consenso em torno das ideologias do capital, visto que esses apresentam um poder de persuasão muito maior do que qualquer indivíduo ou grupo social isoladamente. Desse modo, por utilizar a legitimidade do Estado e de suas instituições, os intelectuais orgânicos coletivos acabam por ter maior legitimidade na disputa em torno do consenso do que os demais tipos de intelectuais.

Conforme indicado por Saviani (2012), a consolidação do CBPE e dos Centros Regionais de Pesquisas Educacionais, foram fundamentais para a alteração na concepção do próprio Instituto Nacional de Estudos Pedagógicos, pois as pesquisas e análises envolvendo as Ciências Sociais suplantaram a psicologia da educação, que até então uma marca desse órgão, herança da influência de Lourenço Filho, difusor das bases psicológicas do movimento renovador da educação no Brasil.

A instauração da Ditadura Militar no Brasil, por meio do golpe de março de 1964, levou a cassação dos direitos políticos e consequentemente, ao fim do período 
em que Anísio Teixeira, ocupou simultaneamente os cargos de DiretorGeral do Instituto Nacional de Estudos Pedagógicos e de Secretário-Geral da CAPES.

\subsection{A crise quase terminal do INEP}

O aprofundamento da ditadura militar levou à aquele que seria o período mais penoso da história do Instituto Nacional de Estudos Pedagógicos, isto porque entre 1972 e 1996, as suas funções, sobretudo, aquelas relacionas a pesquisa e a perde paulatinamente as suas funções, chegando a compor uma lista de órgãos passíveis de extinção durante o governo de Fernando Collor (MARIANI, 1982; ROTHEN, 2008; SAVIANI, 2013).

Com a instauração da Ditadura Militar, Anísio Teixeira foi substituído na diretoria geral do Instituto Nacional de Estudos Pedagógicos pelo empresário do ensino Privado, oriundo do estado de São Paulo, Carlos Pasquale. Em 1966, Carlos Pasquale foi substituído pelo também paulista, professor da Universidade de São Paulo (USP), Carlos Corrêa Mascaro, que iniciou a desarticulação das atividades do órgão. Com isso, as atividades do Instituto Nacional de Estudos Pedagógicos ficaram reduzidas a atuação na execução de projetos em conjunto com os organismos internacionais, a coleta de documentação e informação, levantamento bibliográfico e a publicação das revistas especializadas, "RBEP", "Em Aberto" e "Informativo INEP". Nesse mesmo período, em paralelo ao desmonte do órgão, houve o lançamento de duas iniciativas, o Programa Anísio Teixeira, que visava incentivar estudos, levantamentos e pesquisas educacionais, e o Programa Lourenço Filho, destinado a criar um subsistema de documentação e informação educacional.

Paradoxalmente, um dos períodos de maior tensão na história do INEP, teve início com a publicação do Decreto no 71.407/1972, que dentre outras medidas, alterou a nomenclatura do Instituto Nacional de Estudos Pedagógicos para Instituto Nacional de Estudos e Pesquisas Educacionais, denominação empregada pelo órgão, até o presente. Ao alterar a nomenclatura do instituto, foi incorporada a palavra "pesquisas", e feita a substituição do termo "pedagógicos" por "educacionais, o que poderia ser explicado, segundo Saviani (2012), pela implementação dos programas de pós-graduação voltados para o desenvolvimento da pesquisa no país. Além disso, a educação representa uma categoria mais amplamente reconhecida do que pedagogia.

Para além das motivações da alteração na sua nomenclatura, a subordinação do Instituto Nacional de Estudos e Pesquisas Educacionais ao Secretário Geral do MEC, como determinou o parágrafo único do artigo 1ㅇ do Decreto no 71.407/1972, representou uma significativa perda de autonomia do órgão, que anteriormente estava submetido diretamente ao ministro de Estado da Educação e Cultura.

Coube a professora Maria Mesquita da Siqueira, nomeada Diretora-Geral pela Portaria GM no 38/1976, a responsabilidade pela transferência definitiva do Instituto Nacional de Estudos Pedagógicos para Brasília. Ainda sob sua gestão, foi publicado o Decreto no 79.809/1977, que apesar de preservar as atribuições do Instituto Nacional de Estudos e Pesquisas Educacionais, colocava fim a um dos principais legados de 
Anísio Teixeira na Direção-Geral do órgão. Assim, é decretado suscintamente, em seu artigo 2 que "Fica extinto o Centro Brasileiro de Pesquisas Educacionais, criado pelo Decreto no 38.460, de 28 de dezembro de 1955". Diante da eminente transferência do Instituto Nacional de Estudos e Pesquisas Educacionais para Brasília e da extinção do CBPE, a sua Biblioteca foi doada para o Centro de Filosofia e Ciências Humanas (CFCH), da Universidade Federal do Rio de Janeiro (UFRJ), para compor a biblioteca da PósGraduação em Educação (SAVIANI, 2013).

Durante a década de 1980, as atividades do Instituto Nacional de Estudos e Pesquisas Educacionais se reduziram basicamente ao financiamento de estudos e pesquisas sobre a educação, cultura e desporto e ao levantamento de produção bibliográfica. A edição da RBEP chegou a ser suspensa entre 1980 e 1983, ainda que nesse período, tenham sido editadas outras duas publicações, que estão em circulação até o momento, a revista Em Aberto e o Informativo do INEP (SAVIANI, 2013). Além disso, a sua atuação ficou completamente subordinada ao MEC, perdendo a independência conquista por Lourenço Filho e reiterada na gestão de Anísio Teixeira.

Assim, o outrora prestigiado Instituto Nacional de Estudos e Pesquisas Educacionais, que chegou a ter a sua estrutura física e organizacional comparada à do MEC (Bonamino, 2018), chega em meados da década de 1990, com cerca de 10 servidores que ocupavam algumas salas na Universidade de Brasília (UnB).

\subsection{A transformação do INEP em agência avaliadora da educação nacional}

A transformação do INEP em agência avaliadora da educação nacional foi consequência da implementação da reforma gerencial do aparelho do Estado no campo educacional, que no Brasil teve suas origens no governo Sarney, mas que foi empreendida de maneira sistematizada durante o governo Fernando Henrique Cardoso. Para um dos principais intelectuais orgânicos da reforma gerencial do aparelho estatal brasileiro, o economista Luiz Carlos Bresser Pereira, ex-ministro da Administração Federal e Reforma do Estado (MARE), a reforma gerencial do aparelho estatal se fazia necessária, pois, com a redemocratização e a promulgação da constituição de 1988, as despesas sociais cresceram consideravelmente, fazendo com que o Estado perdesse a sua capacidade promover o crescimento econômico e o desenvolvimento social (BRESSER-PEREIRA, 1998). Nesse ponto, encontra-se o principal argumento, para justificar a imprescindibilidade de uma reforma gerencial, em torno do processo de desmantelamento dos direitos sociais, como o trabalhista, previdenciário, de saúde e educação.

Cabe destacar ainda, que a avaliação dos sistemas educacionais nacionais, deriva das recomendações expressas pelos organismos internacionais nas diretrizes para a educação, contidas nos contratos estabelecidos entre esses órgãos e os países contratantes de empréstimos. Tal cenário é corroborado por Castro, ao afirmar que "a ênfase na avaliação como instrumento de monitoramento do sistema entrou fortemente na agenda das políticas educacionais desde meados da década de 1990" (CASTRO, 2016, p. 86). 
Para a ex-secretária executiva do MEC e ex-presidente do INEP, Maria Helena Guimarães de Castro (2016) a implementação da reforma gerencial no campo educacional e o estabelecimento de um sistema nacional de avaliação educacional para os diferentes níveis de ensino, se faziam necessários desde a promulgação da Constituição Federal de 1988.

Ainda segundo Castro (2016), o aumento da vinculação dos percentuais mínimos do orçamento público destinado a educação, também previsto na Constituição Federal de 1988, foi a principal mudança institucional que demarcou a agenda de reformas da educação estabelecida no governo Fernando Henrique Cardoso.

A reforma gerencial do campo educacional fica evidente a partir de alterações legislativas. Nesse contexto, foram promulgadas a Lei $n$ o 9.394/1996, que estabeleceu as Diretrizes e Bases da Educação Nacional (LDB) e a Lei no 9.448/1997, que reestruturou o INEP. Assim, com a sua reestruturação, o INEP passa o organismo responsável pela avaliação, acreditação e ranqueamento da educação escolar, tanto pública como privada, estabelecida pela LDB. Com a reestruturação promovida pela Lei no 9.448/1997, o INEP passa de um órgão governamental que desde o estabelecimento das suas funções vinha se ocupando de estudos e pesquisas educacionais para se transformar no organismo responsável por avaliar e acreditar os sistemas de ensino do Brasil. Cabe destacar que para Bonamino (2002, p. 115) "a política do INEP no campo da avaliação vem sendo conduzida como política do governo central ou do grupo no poder".

As decisões governamentais sobre avaliação tendem a prescindir de um diálogo prévio com os diferentes níveis educacionais, seja porque sua implementação não propicia a colaboração entre os sujeitos interessados, ou, ainda, porque não envolve suficientemente as instâncias acadêmicas na discussão crítica do que está sendo produzido.

Estes fatores repercutem na legitimidade da avaliação bem como intensifica o risco de desarticulação das políticas educacionais em virtude das mudanças de dirigentes, em virtude de ingerências políticas. Nesse período, passam a ser de responsabilidade ou desenvolvidos pelo INEP as seguintes avaliações educacionais em larga escala: o SAEB (1990), Provão (1996) e o ENEM (1998).

A cooperação entre o INEP e os organismos internacionais, ao menos no que possibilitou a pesquisa bibliográfica até o momento, remonta a década de 1950 . Sobre essa cooperação, Mariani (1982) afirma que a criação em 1953 do Centro de Documentação Pedagógica (CDE) do INEP contou com as sugestões do técnico da UNESCO, Herbert Coblans.

Além de definir novas atribuições para o INEP, a Lei no 9.448/1997, também foi responsável por modificar substancialmente a estrutura administrativa até então existente desse órgão. Ao analisarmos essa nova estrutura administrativa, chama a atenção, a importância que os mecanismos de avaliação educacional passam a desempenhar, inclusive passando a nomear duas das quatro diretorias criadas. Posteriormente, com a edição do Decreto no 2.146/1997 foram definidas as quatro diretorias que comporiam a administração desse órgão, que são: Diretoria de 
Avaliação da Educação Básica, Diretoria de Informações e Estatísticas Educacionais, Diretoria de Avaliação e Acesso ao Ensino Superior e Diretoria de Disseminação de Informações Educacionais.

\section{Aprofundamento das políticas avaliativas e sofisticação dos instrumentos de controle do trabalho educativo}

A reestruturação promovida pela Lei no 9.448/1997 levou o INEP a assumir o protagonismo na reforma gerencial dos sistemas educacionais brasileiros. Tal papel passou a ser exercido por meio da coleta de microdados educacionais, o fomento ao desenvolvimento de sistemas de avaliação da educação básica e da educação superior. Além desses fatores, o estabelecimento de um sistema nacional de avaliação educacional e de um sistema de informações educacionais, gerido pelo INEP, levou a conformação política e ideológica nos limites do ideário gerencialista: eficiência, meritocracia, accoutability, despolitização da política e racionalização financeira, da classe trabalhadora da educação.

Essas políticas públicas de avaliação e informações educacionais, bem como de organização das informações e estatísticas educacionais criadas ou reestruturadas durante o governo Fernando Henrique Cardoso, foram consolidadas e aprofundadas nos governos Lula da Silva e Dilma Rousseff.

Como marco dessas políticas de controle do trabalho educativo, cabe destacar a criação de um sofisticado Sistema de Informações Educacionais, que possibilitou a elaboração de um sofisticado sistema dados e informações estatístico-educacionais. Sobre o Sistema de Informações Educacionais, Castro afirma que "é um instrumento básico de avaliação, planejamento e auxílio do processo decisório para o estabelecimento de políticas de melhoria da educação brasileira" (CASTRO, 2000, p. 122).

\subsection{Consolidação da avaliação educacional em larga escala no Brasil}

No século XIX, a busca pelo estabelecimento de padrões nacionais que independessem exclusivamente das orientações e preferências das escolas e professores levou à "criação de um sistema de exames de certificação de conclusão da etapa de estudos equivalente ao ensino secundário na Europa" (SCHWARTZMAN, 2011, p. 17). Entretanto, o modelo de avaliação educacional em larga escala, adotado no Brasil pelo INEP, a partir da década de 1990, teve origem no programa de avaliação educacional do Programa de Expansão e Melhoria da Educação no Meio Rural do Nordeste (EDURURAL).

Para Schwartzman, um marco para uma mudança significativa nas avaliações educacionais pode ser identificado a partir da publicação do Coleman Report, em 1966. O Relatório Coleman foi um estudo realizado por solicitação do governo federal estadunidense com aproximadamente 600 mil estudantes de 4 mil escolas dos Estados unidos da América. Em 1969, foi criado por deliberação do Congresso 
estadunidense o National Assessment of Educational Progress (NAEP), que foi o modelo para a elaboração do SAEB (SCHWARTZMAN, 2011, p. 20).

Como atesta Afonso (2002) temos observado desde a década de 1980, como decorrência da implementação dos planos de governo dos candidatos alinhados com a ideologia neoliberal, tanto em sua vertente conservadora como naquela mediada pela terceira via, de um crescente interesse pela avaliação das políticas públicas. Tal situação acabou produzindo a expressão Estado Avaliador, utilizada para designar a forma como "o Estado vem adoptando um ethos competitivo, neodarwinista, passando a admitir a lógica do mercado, através da importação para o domínio público de modelos de gestão privada, com ênfase nos resultados ou produtos dos sistemas educativos" (AFONSO, 2002, p. 49).

Embora tenham ocorrido algumas experiências anteriores, no início dos anos 1990 o Brasil havia implementado apenas um sistema de avaliação educacional em larga escala, o SAEB, em uma década, entretanto, tanto a educação básica como a educação superior passaram a serem avaliadas regularmente por 3 exames nacionais e 2 exames internacionais. No campo interno se constituíram o SAEB, em 1990, o ENC, em 1996 e o ENEM, em 1998. No campo internacional, o país passou a participar do PERCE em 1997 e do Pisa a partir dos anos 2000. Ainda no que se refere aos sistemas de avaliação do ensino brasileiro, desde o início dos anos 2000, diferentes universidades brasileiras vêm sendo avaliadas, tanto em nível nacional como internacionalmente, por empresas públicas, privadas e instituições educacionais que produzem diversos rankings internacionais. Estes rankings comparam e estabelecem hierarquias com base no fator de impacto e na produção científica dessas instituições.

Para além da transferência do fundo público para o capital nacional e internacional, a adoção pelo Estado brasileiro dos pressupostos da pedagogia política do capital, por meio da implantação dos sistemas de avaliação educacional em larga escala, busca a conformação da classe trabalhadora para o ideário da empregabilidade. Assim, vivenciamos, como nos países europeus, onde os exames educacionais acabaram sendo utilizados como instrumento de manutenção das desigualdades sociais, por parte da burguesia, pois estabeleceram uma hierarquia de oportunidades para os estudantes melhores colocados, garantindo a esses o acesso ao ensino superior e por consequência aos postos de emprego melhores remunerados.

Como forma de consolidar uma "cultura avaliativa", que vinha sendo implementada no país desde a segunda metade dos anos 1980, e objetivando a formação de novos intelectuais alinhados com a pedagogia política do capital, o INEP em parceria com a CAPES e o Grupo Banco Mundial, publicaram, em 1999, um edital com o objetivo de financiar a criação de centros de pesquisas sobre avaliação educacional ligados às universidades brasileiras (CASTRO, 2016). Foram selecionados cinco projetos que foram implementados a partir do financiamento deste edital, a saber: o Grupo de Avaliação e Medidas Educacionais (GAME) da Universidade Federal de Minas Gerais (UFMG); o

Centro de Políticas Públicas e Avaliação da Educação (CAEd) da Universidade Federal de Juiz de Fora (UFJF); o Centro de Avaliação da Universidade Federal da 
Bahia (UFBA); o Centro de Pesquisas em Avaliação da Universidade Estadual de Londrina (UEL); e o Centro de Avaliação da Pontifícia Universidade Católica do Rio de Janeiro (PUC-Rio).

Para Castro (1996), uma das representantes da fração que se tornou hegemônica no campo educacional, esclarece que a reforma gerencial do campo educacional iniciado no governo Fernando Henrique Cardoso não apenas teve continuidade, mas foi aprofundada durante o governo Lula da Silva e Dilma Rousseff.

Por fim, a continuidade e o aprimoramento das avaliações nos últimos 20 anos, apesar das sucessivas trocas de ministros e dirigentes do MEC, sugerem um ponto fora da curva na história educacional do país, tão marcada por descontinuidades (CASTRO, 1996).

\section{Conclusões}

Apesar de ter sofrido inúmeras alterações nas suas atribuições e estrutura ao longo de sua história, com a reforma gerencial do aparelho do estado no campo educacional, implementada a partir da década de 1990, era necessária a criação de uma instituição capaz de promover a conciliação entre os diferentes projetos educacionais e ao mesmo tempo, com legitimidade frente aos diferentes atores que disputavam a hegemonia em torno do campo educacional. Assim, o INEP se tornou o organismo responsável por regular os sistemas educacionais brasileiros, formulando, sistematizando e divulgando o projeto político e pedagógico do capital.

Neste sentido, cabe destacar, o papel que os organismos internacionais desempenharam na definição das políticas sociais e de uma pedagogia política do capital nos países periféricos. O aprimoramento do entendimento da reforma gerencial do aparelho estatal e dos impactos que esta teve sobre a educação nacional é outra contribuição dessa tese para o campo educacional.

Finalmente, cabe salientar que durante a realização do levantamento bibliográfico, revisão de literatura e análise de fontes primárias e secundárias, encontramos elementos que sugerem que a reestruturação do INEP, que até então era um órgão esvaziado de suas funções na estrutura do MEC, se insere em um contexto de crescente influência dos organismos internacionais, em especial do Grupo Banco Mundial, na definição das políticas educacionais no Brasil. Tais elementos são reforçados quando comparamos as atribuições definidas para o INEP pela Lei $n$ ㅇ 9.448/1997 e os objetivos dos projetos financiados pelo GBM no setor educacional brasileiro, uma vez que, a melhoria da qualidade e na eficiência do ensino estão entre os objetivos prioritários dos projetos de cooperação técnica estabelecidos entre o governo brasileiro, alguns de seus estados e o GBM (TOMMASI, 1996). Para atender a tais pressupostos o GBM definiu nos acordos de cooperação técnica para a área educacional acordados com as seguintes medidas, que em última instância, são basicamente as mesmas estabelecidas com a reestruturação do INEP, que são: estabelecimento de indicadores de qualidade; implantação de sistema de monitoramento e informação; melhoria na coleta e geração de dados; implementação 
de sistema de avaliação do desempenho de professores e alunos; desenvolvimento de estudos e pesquisas sobre gestão escolar; elevação da capacidade de gerenciamento das políticas educacionais; e definição de políticas de accoutability.

\section{Referências}

AFONSO, Almerindo Janela. Avaliação Educacional: regulação e emancipação. São Paulo: Cortez, 2002.

BONAMINO, Alicia. Tempos de avaliação educacional: o SAEB, seus agentes, referências e tendências. Rio de Janeiro: Quartet, 2002.

BRASIL. Lei no 378, de 13 de janeiro de 1937. Dá nova organização ao Ministério da educação e Saúde Pública. Rio de Janeiro (DF): 1937. Disponível em: https://www2.camara.leg.br/legin/fed/lei/1930-1939/lei-378-13-janeiro1937398059-veto-75139-pl.html . Acesso em: 21 fev. 2018.

BRASIL. Decreto-Lei no 580, de 30 de julho de 1938. Dispõe sobre a organização do Instituto Nacional de Estudos Pedagógicos. Rio de Janeiro (DF): 1938. Disponível: http://www2.camara.leg.br/legin/fed/declei/19301939/decreto-lei-580-30-julho1938-350924-publicacaooriginal-1-pe.html. Acesso em: 21 fev. 2018.

BRASIL. Lei no 9.394, de 20 de dezembro de 1996. Estabelece as diretrizes e bases da educação nacional. Brasília (DF): 1996. Disponível em: http://www.planalto.gov.br/ccivil_03/LEIS/I9394.htm. Acesso em: 23 maio 2018.

BRASIL. Lei no 9.448, de 14 de março de 1997. Transforma o Instituto Nacional de Estudos e Pesquisas Educacionais Anísio Teixeira - INEP em Autarquia Federal, e dá outras providências. Brasília (DF): 1997. Disponível em:

http://www.planalto.gov.br/ccivil_03/Leis/L9448.htm. Acesso em: 23 maio 2018.

BRESSER-PEREIRA, Luiz Carlos. A Reforma do Estado dos anos 90: lógica e mecanismos de controle. Lua Nova, São Paulo, no45, p.49-95, 1998.

CASTRO, Maria Helena Guimarães de. Sistemas Nacionais de Avaliação e de Informações Educacionais. São Paulo em Perspectiva, São Paulo, n. 14, p.121-128, jan/fev/mar. 2000.

CASTRO, Maria Helena Guimarães de O SAEB e a Agenda de Reformas Educacionais: 1995 a 2002. Em aberto. Brasília (DF), v.29, n.96, p. 85 - 98, mai./ago. 2016.

GRAMSCI, Antonio. Os Intelectuais e a Organização da Cultura. Rio de Janeiro: Civilização Brasileira, 1991. 
MACEDO, Jussara Marque de. Formação para o Trabalho Docente. Curitiba (PR): Appris, 2017.

MARIANI, Maria Clara. Educação e Ciências Sociais: O Instituto Nacional de Estudos e Pesquisas Educacionais. In: SCHWARTZMAN, Simon (Org.). Universidades e Instituições Científicas no Rio de Janeiro. Brasília (DF): Conselho Nacional de Desenvolvimento Científico e Tecnológico (CNPq), 1982.

MENDONÇA, Ana Waleska; XAVIER, Libânia Nacif (Orgs.). Por uma Política de Formação do Magistério Nacional: o INEP/MEC dos anos 1950/1960.

Brasília (DF): INEP, 2008.

ROTHEN, José Carlos. O Inep com seus 70 anos: um senhor maduro em constante busca de sua identidade. In: MORAES, Jair Santana (Org.). O INEP na visão de seus pesquisadores. Brasília: INEP, 2008.

SAVIANI, Demerval. História das Ideias Pedagógicas no Brasil. Campinas (SP): Autores Associados, 2013.

SCHWARTZMAN, Simon. As avaliações de nova geração. In: SOUZA, Alberto de Mello e (Org.). Dimensões da Avaliação Educacional. Petrópolis (RJ): Vozes, 2011.

SCHWARTZMAN, Simon Crise orgânica do capital, recomposição burguesa e intensificação da precariedade do trabalho docente: fundamentos sócio-históricos da (des)configuração do trabalho docente. 38a REUNIÃO NACIONAL DA ANPED, 01 a 05 de outubro de 2017, UFMA, São Luís/MA. Anais... São Luís (MA), ANPED, 2017. Disponível em:

http://38reuniao.anped.org.br/sites/default/files/resources/programacao/sess oes_38anped_2017_4_desconfiguracao_do_trabalho_docente_texto_jose_dos_sant os.pdf. Acesso em: 27 fev. 2018.

TEIXEIRA, Anísio. Discurso de posse do Professor Anísio Teixeira no Instituto Nacional de Estudos Pedagógicos. Revista Brasileira de Estudos Pedagógicos, Rio de Janeiro (DF), v.17, n.46, p. 69-79, abr./jun. 1952.

TOMMASI, Lívia de. Financiamentos do Banco Mundial no Setor Educacional Brasileiro: os projetos em fase de implementação. In: TOMMASI, Livia de; WARDE, Mirian Jorge; HADDAD, Sérgio (Orgs.). O Banco Mundial e as Políticas Educacionais. São Paulo: Editora Cortez. /PUC-SP/Ação Educativa, 1996.

VIANA FILHO, Luís. Anísio Teixeira: a polêmica da educação. São Paulo: Editora Unesp; Salvador: EDUFBA, 2008. 